\title{
Impact of Heads' Teachers' Supervision on Secondary School Performance in Bannu Division
}

\author{
Wali Ullah $^{1^{*}} \quad$ Muhammad Ayaz $^{2} \quad$ Zahid Ullah $^{1} \quad$ Nasir Ali $^{1} \quad$ Abdul Shahab Khan ${ }^{1}$ \\ Abdul Basit Khan ${ }^{1} \quad$ Tanveer Ahmad ${ }^{3}$ \\ 1.Institute of Education \& Research, University of Science \& Technology, Bannu \\ 2.Chaireman, Department of Education \& Research, University of Lakki Marwat \\ 3. Quartuba University of Science \& Information Technology Peshawar
}

\begin{abstract}
To highlight the important role of teachers' supervision by head in Secondary School is the main purpose of this paper. Nature of this study was descriptive. Attempt was made to examine the impact of teachers' supervision by heads' on Secondary schools performance. The secondary schools' teachers and $10^{\text {th }}$ class students' record made the population of the study. The sampled respondents were 330 out of 1650. Questionnaire of five point Likert scale was utilized for data collection. Analysis of data was made through SPSS (Version 16.0). Through utilizing Linear Regression; the impact of teachers' supervision by heads on Secondary school performance was analyzed. The results showed that there is clear impact of teachers' supervision on Secondary school performance.
\end{abstract}

Keywords: Head of School, Teachers' supervision, Public School, Private School, Bannu division.

DOI: $10.7176 / \mathrm{JEP} / 10-36-12$

Publication date: December $31^{\text {st }} 2019$

\section{INTRODUCTION}

According to e-dictionary, supervision is overseeing the specific activities to perform them in an effective way. Or utilization of people for better performance (Daresh, 2001; Gebhard, 1990; Drasce\& Roe, 1999) According to them supervision in education perspective is that, head (supervisor) of institution observe the continue activities of teachers during teaching and make improvement for better performance. According to (Glikman et al, 1998) supervision is a process which teacher needs are kept in focused to achieve the desired goals/vision in a better way.

(Goldhamoner et al , 1980) explained that supervision by head of institution was that to provide leadership and to owe the institutions of teachers, to select and revise better educational objectives, to motivate them for better professional growth and development, to guide them in a better way (methods, instructions, evaluations)

(Quraishi; \&Khatoon, 2008) explained that supervision of institution should improve the schools' teachers' skills, should co-ordinate with all the stake holders, related with them by keeping in mind the educational goals for the improvement of overall students' performance. Head should work with all the teaching, non-teaching staff, students and their parents.

According to the report published by (UNESCO, 1993), the process of supervision by head involves.

$>$ To provide supervision to the teachers in selection of relevant materials for instructions.

$>$ The duty of assigning different subjects in School to the teachers keeping in observation their specialized competencies and skills.

$>$ The duty of providing professional leadership to teacher for solving of various troubles faced by teachers and students in their Secondary schools.

$>$ To measure, estimate and to supervise deeply methods of teaching of various teachers.

$>$ To offer positive and confidante environment to teaching and learning process in schools.

\section{RELATED LITERATURE}

Teachers play a key role in successful instructions while supervision play vital role to effectively accomplish goals and helps teachers to be succeed. (Glickman et al., 1998) Supervision is a continuous process in which individual interact with group of individuals to achieve their goals and visions effectively and efficiently by keeping in mind the needs of that group(teachers). Glickman etal, 1998 \&Poole, 1994) states that "Supervision is a growing and developing process for teachers' teaching and students' learning.

The main aim of the supervision is to achieve the goals in effective way. According to Drak\& Roe, 1999) all the activities performed in a school by head of the institution like administration as well management, supervision play a key role in their performance improvement by general overseeing the activities. "Supervision interact the entire discrete activities/elements combine together to build effective instruction" (Glickman et al, 1998).

According to (Pfeiffer \& Dunlap, 1982) supervision of instructions is a comprehensive, interpersonal process which dealing behaviors of teachings, the curriculum of their concerned institutions, environment of learning, students' grouping, teachers' utilization, and the teachers' professional development. 
All hard works of designated school officials which are directed toward providing leadership to school teachers and other instructive workers, the main purpose of which is to improve the instruction; involves to stimulate the specialized growth and professional progress of teachers, involves in selecting and revising of educational objectives, involves in instructing materials, and methods of teaching, and the evaluation of instructions.

\section{Purposes of Supervision}

$>$ The basic aim of supervision is the development of students' growth, their promotion and to provide them encouraging environment which ultimately promote human relations in the society. (Wiles \&Bondi, 1996).

$>$ Leadership is a basic quality which must be in students for adaptation in the environment. Supervision is consistent activity which provides leadership to students and helped them in various stages of their learning in school. Leadership also provides consistency to students for acquiring various learning activities within the learning environment of school.

$>$ The major aim of teachers' supervision is to provide an interesting and favorable environment in the school settings so that children get more and more learning and instruction. Supervision is the most effective tool of teachers' teaching improvement. (Beach \&Reinharts, 2000; Glickman et al, 1998; Goldsberry, 1997; Nolan, 1997; Sergiovanni \& Starratt, 1998; Waite, 1997)

$>$ Methods of teaching and learning can be improved by inspecting it thoroughly and supervision is the tool facilitates and improves teaching methods and can also help in specialized growth of teachers. ( Acheson \&Gall, 1997; Glatthorn, 1984)

$>$ Supervision help in creating a physically, socially, psychologically developed environment favorable for students' learning and will help the teachers to become aware of their teachings, methods of teachings and its consequences favorable for students (Nolan, 1997; Wanzare\& Da Cost, 2000)

$>$ Supervision helps in co-coordinating and integrating all educational efforts taking place in the institution like school and materials, and also help in providing continue supply in the school.

$>$ Supervision helps the head in enlisting the collaboration of all staff members serving his institution and helps in providing prevention of teaching difficulties in the institution.

$>$ Supervision helps in aiding, inspiring, leading and developing the sense of security in teachers which liberates the creative mind of teachers towards their learners.

$>$ Supervision helps in enabling the teachers to try out new methods of instruction in a very safe and supportive environment (Nolan, 1997)

$>$ Supervision by head helps in fostering teachers' motivation and also helps in the development of curriculum (Oliva \& Pawlas, 1997; Nolan, 1997)

$>$ Supervision by head in the institution helps in monitoring the teaching-learning process composed by teacher to get the best outcome for students (Schain, 1988, Nolan \& Francis, 1992).

\section{STATEMENT}

The significance and importance of teachers' supervision in students' success, particularly in the achievement of academic success and on the whole Secondary schools performance is undeniable. Supervision is a part of teacher education and is continued activity in which the supervisor takes interest to see that what does go on in the class room in order to improve the instruction of teachers. In Bannu division of Khyber Pakhtunkhawa, more than $50 \%$ students, had secured grade $\mathrm{C}$ or below 50\% in secondary school examination in 2014-2015. There may be so many factors of this low performance but the researcher focused on "Impact of teachers' supervision by head on Secondary School performance in Bannu Division”.

\section{STUDY OBJECTIVES}

$>$ To investigate the impact of teachers' supervision by the heads on Public Secondary school performance in Bannu division.

$>$ To examine the impact of teachers' supervision by heads on Private Secondary schools performance in Bannu division.

\section{RESEARCH HYPOTHESES}

$>$ There is no significant impact of teachers' supervision by heads on Public Secondary school performance in Bannu division.

$>$ There is no significant impact of teachers' supervision by heads by on Private Secondary school performance in Bannu division. 


\section{METHODOLOGY OF RESEARCH}

Nature of the study was descriptive. Secondary school teachers (boys and girls) of Public and Private, and $10^{\text {th }}$ class students' record in Bannu division (District Bannu and District Lakki Marwat) were comprised of population. A method of proportionate (stratified) random sampling was utilized for taking sample. 330 out of 1650 Secondary school (boys and girls) teachers from Bannu division keeping in view formula of John Curry (1984). 36 Secondary schools out of 214 were selected taking samples of the population in Bannu division.

\section{Sample Size Rule of Thumb}

If population is 10 to 100 , then it will be taken as $100 \%$

If population is 101 to 1000 , then it will be taken as $10 \%$

If population is 1001 to 5000 , then it will be taken as $5 \%$

If population is 5001 to 10000 , then it will be taken as $3 \%$

If population is $10000+$, then it will be taken as $1 \%$

\section{Demographic Information of respondents (330)}

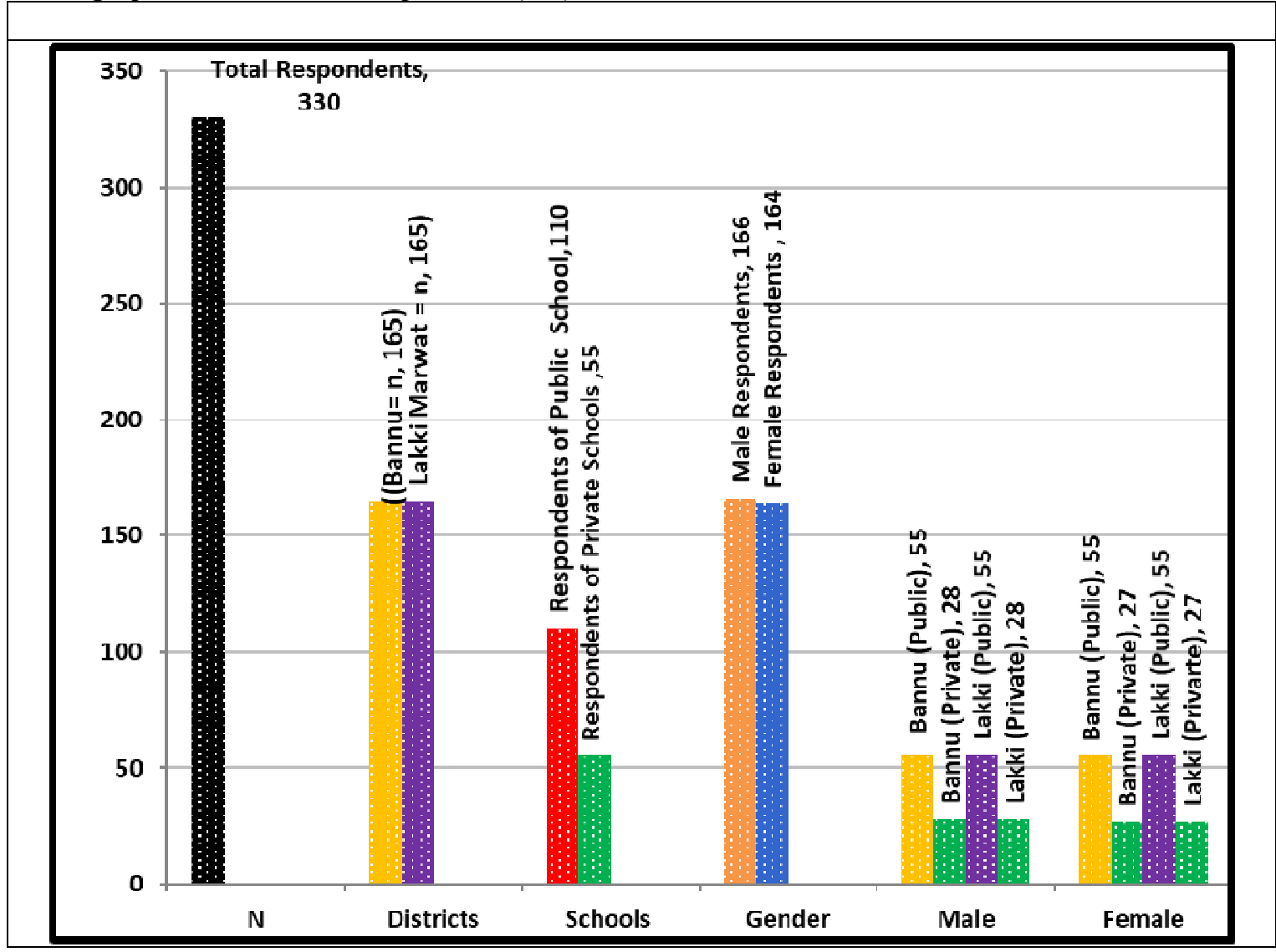

\section{INSTRUMENTATION}

Through closed Likert type of questionnaire, data was collected.

\section{DATA COLLECTION PROCEDURE}

The data was collected during regular school time in the second term of 2015/2016 academic session. The researcher visited the sampled schools personally and sought permission first from the respective schools' principals/head teachers to allow him to school for data collection. After allowing, the researcher personally administered the questionnaire of data collection. This questionnaire which was assign to teachers of public and private secondary schools for taking response from teachers and dually filled up questionnaires were return by the respondents. Researcher got 100\% filled questionnaire.

\section{PILOT TESTING}

Pilot testing comprised of validity and reliability. Researcher prepared self-structured questionnaire and to 
improve the validity, the researcher sought help from the experts of the Universities, of Bannu and D.I.khan. After getting the opinions about questionnaire from experts, researcher finalized questionnaire having items 46 .

The researcher determined the reliability of this questionnaire, when researcher collected responses from 50 public and private (boys and girls). The views of the teachers were fed-up in SPSS (version-16). The views were processed and a questionnaire of 43 items was obtained at last. Cronbach's Alpha was .809 and three items were dropped, because their item-total correlation was less than .25 .

\section{DATA ANALYSIS}

For data analysis, two hypotheses $\mathrm{H} 01$ and $\mathrm{H} 02$ were tested by using linear regression and after testing, it was seen that H01 and H02 were rejected and on the basis of rejection of hypotheses, it was concluded that teachers' supervision by heads of Public and Private Secondary schools have impacted the performances of Secondary schools in Bannu division.

RESULTS AND DISCUSSION

Table 1.3 Regression model showing the impact of teachers' supervision by head on Public Secondary school performance

\begin{tabular}{|c|c|c|c|c|c|}
\hline Predictor & $\mathbf{R}^{\mathbf{2}}$ & $\boldsymbol{\beta}$ & S.E & t-ratio & P-value \\
\hline Public Schools' Teachers' supervision & .168 & 2.063 & .311 & 6.638 & .000 \\
\hline
\end{tabular}

Table 1.4 Regression model showing the impact of teachers' supervision by head on Private Secondary school performance.

\begin{tabular}{|c|c|c|c|c|c|}
\hline Predictor & $\mathbf{R}^{2}$ & $\boldsymbol{\beta}$ & S.E & t-ratio & P-value \\
\hline Private Schools' Teachers' supervision & .057 & .602 & .237 & 2.544 & .000 \\
\hline
\end{tabular}

$\mathrm{p}<.05, .01$

\section{DISCUSSION}

Table 1.3 presents results of the regression on predicting the average academic achievement through teachers' supervision. The model list of the predictors, which best explains the academic achievement. The $\mathrm{R}^{2}$ value is 0.168 , which depicted that $16.8 \%$ variation in the School performance was explained by the independent variable teachers' supervision by heads of Public secondary school.

Column1 of table 1.3 shows that a unit change in teachers' supervision by heads of public secondary school predicts 2.063 units change in academic achievement of public Secondary schools students.

Standard error of teachers' supervision by heads of public secondary school is 0.311 . T-ratio of teachers' supervision by heads of Public secondary school is 6.638. P-value of teachers' supervision by head of public Secondary schools is .000 which is significant. The significance of P-value rejected the null hypothesis.

Table 1.4 presents results of the regression on predicting the average academic achievement through teachers' supervision. The model list of the predictors, which best explains the academic achievement. The $\mathrm{R}^{2}$ value is 0.057 , which depicted that $5.7 \%$ variation in the School performance was explained by the independent variable, teachers' supervision by heads of Private Secondary schools.

Column 1 of table 1.4 shows that a unit change in teachers' supervision by head of public Secondary schools predicts .602 units change in academic achievement of public secondary school students.

Standard error of teachers' supervision by heads of public secondary school is 0.237 . T-ratio of teachers' supervision by heads of Public secondary school is 2.544. P-value of teachers' supervision by head of public Secondary schools is .000 which is significant. The significance of P-value rejected the null hypothesis.

\section{FINDINGS}

$>$ Second row of table 1.3 indicates that $\mathrm{R}^{2}$ value is $.168, \beta$ is 2.063 , $\mathrm{S}$.E is .311 , t-ratio is 6.638 , and $\mathrm{P}$ value is .000 , which express that teachers' supervision has impact on students' academic achievement. I.e. on Public Secondary school performance in Bannu Division.

$>$ Third row of table 1.4 indicates that $\mathrm{R}^{2}$ value is $.057, \beta$ is .602 , $\mathrm{S}$.E is .237 , t-ratio is 2.544 , and P-value is .000 , which express that teachers' supervision has impact on students' academic achievement. I.e. on Private Secondary schools performance in Bannu Division.

\section{CONCLUSIONS}

Keeping in view the facts and figures given in findings, it is cleared that supervision of teachers by heads in Public Secondary schools has significantly affected (impacted) the Public Secondary schools performance in Bannu Division. Similarly from the facts and figures of Private Secondary schools in Bannu division given in findings it is cleared that supervision of teachers by heads in Private Secondary schools has significantly affected (impacted) the Private Secondary schools performance in Bannu Division. 


\section{ACKNOWLEDGEMENT:}

Mr. WaliUllah is the principal author, Dr. M. Ayaz is the supervisor, Zahid Ullah and Nasir Ali are the Cosupervisors of this paper while Abdul shahab Khan, Abdul Basit and Tanveer Ahmad are the facilitators and financial sponsors of this paper.

\section{References}

Acheson, K. A., \& Gall, M. D. (1997).Techniques in the clinical supervision of teachers: Preserve and inservice applications (4th ed.). New York: Longman.

Alfonso, R. J., \& Firth, G. (1990). Supervision: Needed research. Journal of Curriculum and Supervision, 5(2), 181-188.

Arredondo, D. E., Brody, J. L., Zimmerman, D. P., \& Moffett, C. A. (1995). Pushing the envelope in supervision.Educational Leadership, 53(3), 74-78.

Beach, D. M., \&Reinhartz J. (2000).Supervisory leadership: Focus on instruction.

Boston: Allyn and Bacon.

Bolin, F. S., \&Panaritis, P. (1992).Searching for a common purpose: A perspective on the history of supervision. In C. D. Glickman (Ed.), Supervision in transition: The 1992 yearbook of the Association for Supervision and Curriculum Development (pp. 30-43). Alexandria, VA: ASCD.

Cogan, M. L. (1973). Clinical supervision. Boston: Houghton-Mifflin.

Costa, A. L., \&Kallick, B. (1993).Through the lens of a critical friend.Educational Leadership, 50(1), 49-51

Da Costa, J. L., \& Riordan, G. P. (1997). Teacher efficacy and trust in supervisory relationships. The Canadian Administrator, 36(6), 1-11.

Drake, T. L., \& Roe, W. H. (1999).The principalship(5th ed.). Columbus, Ohio: Prentice-Hall.

Glatthorn, A. A. (1984). Differentiated supervision.Alexandria, VA: Association for Supervision and Curriculum Development.

Glatthorn, A. A. (1990). Supervisory leadership: Introduction to instructional supervision. Glenview, IL: Scott, Foresman/Little, Brown Higher Education.

Glickman, C. D., Gordon, S. P., \& Ross-Gordon, J. M. (1998).Supervision of instruction: A developmental approach (4th ed.). Boston: Allyn and Bacon.

Goldsberry, L. (1997). Do teachers benefit from supervision? Yes. In J. Glanz\& R. F.

Neville (Eds.), Educational supervision: Perspectives, issues, and controversies (pp. 44-55). Norwood, MA: Christopher-Gordon.

Nolan, J. F., Jr. (1997). Can a supervisor be a coach? No. In J. Glanz\& R. F. Neville (Eds.), Educational supervision: Perspectives, issues, and controversies (pp. 100-112). Norwood, MA: Christopher-Gordon.

Nolan, J., \& Francis, P. (1992).Changing perspectives in curriculum and instruction. In C. D. Glickman (Ed.), Supervision in transition: The 1992 yearbook of the

Association for Supervision and Curriculum Development (pp. 44-60). Alexandria, VA: ASCD.

Nolan, J., Hawkes, B., \& Francis, P. (1993). Case studies: Windows onto clinical supervision. Educational Leadership, 50(1), 52-56.

Oliva, P. F., \&Pawlas, G. E. (1997).Supervision for today's schools (5th ed.). New York: Longman.

Pfeiffer, I. L., \& Dunlap, J. B. (1982).Supervision of teachers: A guide to improving instruction. Phoenix, AZ: Oryx Press.

Poole, W. L. (1994). Removing the "Super" from supervision.Journal of Curriculum and Supervision, 9(3), 284309.

Schain, R. L. (1988). Supervising instruction: What it is and how to do it. New York: Educators Practical Press.

Shahid,S.M, (2010) Educational Management and Supervision. Majeed Book Depo, 22 Urdu Bazzar, Lahore

Sergiovanni, T. J. (1992). Moral authority and regeneration of supervision.In C. D.

Glickman (Ed.), Supervision in transition: The 1992 yearbook of the Association for Supervision and Curriculum Development (pp. 203-214). Alexandria, VA: ASCD.

Sergiovanni, T. J., \&Starratt, R. J. (1998).Supervision: A redefinition (6th ed.). New York: McGraw-Hill.

Sergiovanni, T. J., \&Starratt, R. J. (2002).Supervision: A redefinition (7th ed.). New York: McGraw-Hill.

Waite, D. (1997). Do teachers benefit from supervision? No. In J. Glanz\& R. F. Neville (Eds.), Educational supervision: Perspectives, issues, and controversies (pp. 56-70). Norwood, MA: Christopher-Gordon.

Wanzare, Z., \& Da Costa, J. L. (2000). Supervision and staff development: Overview of the literature. NASSP Bulletin, 84(618), 47-54.

Wiles, J., \&Bondi, J. (1996).Supervision: A guide to practice (4th ed.) Englewood Cliffs, NJ: Merrill. 